\title{
RESENHA
}

\section{TIRAR DEUS DO ARMÁRIO}

TAKING GOD OUT THE CLOSET

ALEXANDRE DE OLIVEIRA FERNANDES ${ }^{1 *}$

ORCID: https://orcid.org/0000-0002-1556-4373

SPARGO, Tamsin. Foucault e a teoria queer: seguido de Ágape e êxtase: orientações pós-seculares. Tradução: Heci Regina Candiani; posfácio Richard Miskolci. Belo Horizonte: Autêntica Editora, 2017.

A professora Tamsin Spargo lecionou na Universidade John Moores, em Liverpool, no Reino Unido. É historiadora cultural e escritora, tendo em 2017 dois ensaios publicados no Brasil, pela Autêntica Editora, a saber, Foucault e a teoria queer, seguido de "Ágape e êxtase: orientações pós-seculares". Os textos que ora resenhamos são de interesse para os estudos de gênero, filosofia, ética e religião. Ao leitor se entregam escritos produzidos com leveza e lucidez, certa dose de utopia tão necessária em tempos temorosos como os nossos, de apequenamento do debate e do forçoso convencimento do outro por meio de bombas, sabotagens e bloqueios de toda ordem. Intelectual comprometida com teorizações que iluminam a vida, suas teses descem às ruas, atravessam os muros acadêmicos e se propõem a construir um mundo mais acolhedor à diferença.

A diferença é tema caro à Educação. E hoje sabemos como esta pode ser atacada por discursos fundamentalistas que lhe tentam restringir ações e cooptar seu trabalho, vide projetos como "Escola sem Partido" que até tramitaram em Câmaras Legislativas no Brasil, sustentados pela Bancada Cristã pouco afeita à aceitação da diferença. Importa conhecer o pensamento de Tamsin Spargo porque ele nos convida à ética infinita, por meio de reflexão teórica inusitada, qual seja, pensar que o sujeito queer, fraturado e marginalizado, possa

\footnotetext{
'Instituto Federal de Educação da Bahia, Porto Seguro, BA, Brasil.

"Doutor em Ciência da Literatura (UFRJ), Professor de Língua Portuguesa no IFBA/Porto Seguro, Professor Permanente no Programa de Pós-Graduação em Ensino e Relações Étnico-raciais da UFSB/CSC e Professor Permanente no Programa de Pós-Graduação em Estudos Étnicos e Contemporaneidade da UESB/Jequié. Coordenador do Grupo de Pesquisa em Linguagens, Poder e Contemporaneidade - GELPOC/ IFBA. Email:<alexandre.pro@gmail.com>.
} 
contribuir para provocar o religare, colocando-nos em contato com o inefável, sensibilizando-nos para uma vida em que o diferente seja acolhido na diferença porque, dentre outras razões, está em mim. Acolhido o diferente numa ética queer e pós-secular não faz sentido a vibração fundamentalista que lança aviões contra torres, que invade templos, que não difunde estudos africanos porque não fazem parte da minha cultura. Ao contrário, nesta ética importa uma ação e epistemologias polissêmicas.

Defende Spargo - e esta é a tese do ensaio "Foucault e a teoria queer" - que as bases do pensamento filosófico em que se assentam os estudos queer estão ligadas a Michel Foucault, pensador francês que problematizou o discurso, o saber e o poder. A teoria queer teria se avolumado com a teoria pós-estruturalista e o modelo psicanalítico de identidade descentrada e instável, ganhando densidade com a rasura de estruturas conceituais e linguísticas binárias, próprias da desconstrução de Jacques Derrida.

Durante a leitura, o pesquisador de gênero e afins, terá diante de si o percurso que levou os estudos de Judith Butler, teórica estadunidense amplamente conhecida nos meios acadêmicos brasileiros, a ampliar o argumento foucaultiano de que a sexualidade é produzida no discurso, incluindo o gênero como efeito performativo. Os estudos da filósofa sobre as drags, cuja interpretação hiperbólica e paródica da mulher coloca em xeque noções como verdade e origem, denunciam o mundo como um jogo de paródias, uma coisa sendo a forma "enganadora" da outra, o que permitiu à teoria queer fragilizar noções essencialistas de verdade e a metafísica da presença.

Mas, que nova contribuição teórica pode ser encontrada pelo leitor brasileiro exigente e habituado a discussões de gênero em Spargo? Não bastasse o didático percurso de Foucault à teoria queer disposto no primeiro texto, no segundo ensaio, unindo pensadores diversos como Sara Ahmed, Marcella Althaus-Reid, Judith Butler, Slavoj Zizek, há a defesa de que ágape e êxtase, irmanados com o pensamento queer e a filosofia pós-secular, poderiam colaborar para novos modos de acolhimento ético que transcendam os fundamentalismos, sejam os da ciência ou os da religião.

Em seu livro, Spargo traça um passeio crítico e didático aproximando Michel Foucault da teoria queer, para na sequência nos inquietar com um retorno ao religioso. E por quê? Porque é necessário colocar em questão as evidentes barbáries da religião, o acirramento do fundamentalismo, o consumismo de massa e os absurdos da fé cega na ciência e na razão pós-moderna. Diante do desencanto epistêmico do 
pós-modernismo e da derrocada de narrativas religiosas, se pergunta Spargo se não seria um erro filosófico e psicológico, permitir que nossas decepções tomem a cena levando-nos a rejeitar o religioso e a ética.

Ora, vivemos um tempo em que zelosos guarda-fronteiras tentam coibir a circulação de pessoas à medida que as mercadorias, paradoxalmente, circulam mais livremente. Chamaremos a isso de etnocentrismo e xenofobia, manietados pelos interesses do mercado globalizado. A pós-modernidade deu acolhida a cenas de horror: discussões que problematizem o sexismo, a misoginia e as fobias (homo, bi e trans) têm sido barradas por grupos religiosos em várias cidades dos Estados Unidos, suposto país da liberdade e, a exemplo do que ocorreu no Brasil com o veto à palavra "gênero" no Plano Nacional de Educação, parece que vivemos tempos pouco afeitos ao discurso contrastante. A pauta de religiosos radicais - contra o aborto, em nome da família e dos bons costumes, pela "escola sem partido" - é sustentada por uma leitura literal do religioso e encontra acolhida em representações poderosas espalhadas por vários segmentos da sociedade. A este movimento chamaremos de fundamentalismo.

Que narrativa poderia ocupar a cena legando-nos conforto e certa estabilidade, contrapondo-se ao medo e a ansiedade pósmodernos? A aposta de Spargo é a aproximação teórico-filosófica entre teoria queer e pós-secularismo, numa abertura "diferente" da e para a religião. É o que poderíamos de chamar de um "estranhamento" da religião ou nas palavras de Althaus-Reid, lida por Spargo (2017, p. 78): "é preciso facilitar que Deus saia do armário por um processo de queerização teológica".

Poderá questionar o leitor atento: mas não está o queer - este sujeito estranho e excêntrico - envolvido com a rejeição à metafísica da presença, colocando sob suspeita qualquer ideia de transcendência? Não está desgastada a religião em um tempo em que deuses e mágicas religiosas são leiloados como analgésicos pós-modernos sob púlpitos e por detrás de batinas?

Atenta a estas perguntas, Spargo promove a crítica ao mercado das crenças e assevera que os problemas colocados para o mundo pós-moderno, pós-11 de Setembro - e acrescentemos pós-Auschwitz - exigem testar dois tipos de pensamentos anti-fundacionistas: a teoria queer e o pós-secularismo sobre os percalços de se viver na diferença. Para aqueles que acham que esta não é uma boa opção, relembra-nos que Jacques Derrida em seu Força de lei, ao desconstruir noções como justiça, autoridade e lei, não deixou de se preocupar com a moral e a religiosidade. A religiosidade derridiana, como a de outros pensadores 
que investigam a religião no escopo da "tradição" continental é política e não fundacionista, aberta à diferença e à hospitalidade incondicional.

Acredita a autora que, o diálogo afetuoso entre teoria queer e pós-secularismo - sem que uma teoria se sobreponha a outra, mas que avancem seus limites e fronteiras - favorece maneiras queerizadas de se pensar nossa condição atual, a saber, "a teoria queer pode testar o limite de discursos religiosos que têm apoiado repressões e perseguições" (SPARGO, 2017, p. 79). Ou seja, indo além da transgressão queer, com suas paródias e bricolagens, a teoria queer e o pós-secularismo estão aptas a ofertar uma religiosidade apartada de fundamentalismos, proibições e injunções, cujo foco sempre foi a sexualidade dos fiéis, e talvez forneçam às pessoas que se interessam pelo religioso formas mais acolhedoras de viver e ser feliz, encontrando respostas para suas dores e sofrimentos.

Não é grande novidade a leitura de Spargo acerca de Foucault, qual seja, a de que o pensador francês associou a sexualidade à biopolítica, argumentando que o desejo era normatizado por meio de grosso catálogo da cristandade e dos saberes científicos do século XIX, a apontar as anomalias e os desviantes. Não haveria uma "natureza" da sexualidade, o que, se por um lado, não levou o autor francês a descartar a dimensão biológica que constitui os sujeitos, por outro lado, fez com que considerasse tal categoria em face da experiência e da agência humana, construída, posicionada, marcada por histórias e movimentos socioculturais. Contudo, ao nos lembrar de que após Foucault - e não apenas ele, mas também com as contribuições dos movimentos feministas -, as sexualidades poderiam ser pensadas como categorias construídas pelo saber/poder e não como abertas à "descoberta", tal categoria, nem ligada à natureza biologizante, nem submetida ao crivo religioso e biopolítico, poderia flutuar, cambiante, num movimento descentrado, com poucas pretensões à segurança e à estabilidade, ajudando a desenvolver posições de resistências contingentes e molhadas pela extática.

O queer é esta identidade descentrada, opaca, rizomática e em devir, uma diferença que não se deixa assimilar e abala o status quo. Trata-se de um posicionamento excêntrico, não porque esteja "fora" do centro, mas porque compreende as identidades sem essências; E, aberta ao pensamento filosófico pós-secular, como ágape e êxtase, pode o queer nos ajudar a desenvolver formas de pensar, refletir e fazer avançar a fé. É uma proposta que evoca a convivência com os fiéis e com o religioso, uma ética acolhedora que talvez nos permita o religare com o Outro em nossa condição pós-moderna. 
Abrindo a teoria queer ao religioso, Spargo evoca trabalhos como os de David Halperin, Gayle Rubin, Martha Vinicius, Ciny Patton, Simon Witney, os quais respondendo à interpelação de fazer o queer avançar, cada qual a seu modo, demonstram haver um horizonte de possibilidades, salvaguardado o questionamento de Teresa de Lauretis, segundo o qual haveria em curso cooptação dos estudos queer pela indústria editorial desprovida de profundidade e de conteúdo.

Constrangendo o desejo de consumo, as luzes baixas do capitalismo e o posicionamento da abjeção, Spargo constrói seu "religioso queer", cujo "eu" é impessoal e aberto ao Outro. No lugar da competitividade e da busca pelo lucro desmesurado, teve a autora a ousadia de propor aproximações entre a teoria queer e o pensamento pós-secular, segundo os conceitos de ágape e êxtase.

Eis a reflexão de Spargo: do farto legado de Foucault herdamos condições teóricas para desenvolver a teoria queer, inclusive em contato com a religião. Não há razões para a teoria queer ignorar a religiosidade, uma vez que esta lhe determinou historicamente os espaços e se demonstra campo demasiado aberto à análise, pois, a Igreja é historicamente formada por comunidades organizadas por pessoas do mesmo sexo.

Apropriando-se de Slavoj Zizek, Terry Eagleton, Jacques Derrida, Alan Badiou e Gianni Vattimo, atenta para a "virada religiosa" de um ponto de vista político e não necessariamente fundacionista, questiona, portanto, que contribuições o queer poderia legar ao póssecularismo. Sua proposta coaduna o estranhamento queer ao êxtase religioso. O estranhamento possível entre o queer e a pós-secularidade afirmaria uma teologia, uma antropologia e uma ética que promoveriam a diferença como algo não apenas tolerável, mas desejável. Com dupla ênfase na alteridade e na impossibilidade de verdades essencialistas, ágape, como o amor incondicional e o êxtase com seu maravilhamento pela diferença, aliados aos estudos queer, poderiam encontrar caminhos contra as barbaridades e o fechamento do sentido.

O que pensaria Michel Foucault sobre a correlação entre estudos queer e pós-secularidade? Talvez rejeitasse o proselitismo, o fundamentalismo e o religioso inseridos nas tramas do mercado global capitalista e, atendendo a convite de Spargo, aprofundasse os estudos queer comprometendo-o com o desafio de desenvolver alternativas éticas não excludentes na pós-secularidade.

E não poderia ser de outro modo. Ora, o sujeito queer cuja "identidade" é fraturada, não tem o compromisso com a ilusão da completude. Não se interessa por ocupar "um” lugar, porque é 
sempre deslocado e diferido. Conforme postulações queer, minha formação implica o outro coexistir em mim, logo, não ignora que aquilo que sou depende do Outro.

Se a teoria queer frequentemente se interessa pelas políticas de representação e subalternidade, estudos gays e lésbicos, porque não aceitaria o convite? Estranhar o divino é a proposta a ser analisada, num ético e delicado movimento capaz de retirar Deus do armário. Trata-se de um desafio intelectual e político que pode contribuir para desestruturar o status quo, demover fundamentalismos e ideias em que se assentam o valor e o saber nas sociedades contemporâneas.

\section{Referência}

SPARGO, Tamsin. Foucault e a teoria queer: seguido de Ágape e êxtase: orientações pós-seculares. Tradução: Heci Regina Candiani; posfácio Richard Miskolci. Belo Horizonte: Autêntica Editora, 2017.

Submetido: $18 / 04 / 2018$

Aprovado: 23/10/2018

Contato:

Rod BR 367, R. José Fontana, n. 1, (IFBA) Instituto Federal de Educação da Bahia Porto Seguro|BA|Brasil CEP 45.810-000 